\title{
Schizophrenia Behind the Great Jazz
}

Hersa Aranti ${ }^{\mathrm{a}}$, Elizabeth Kristi Poerwandari ${ }^{\mathrm{b}}$, and Agustin Sukarlan Basric $^{\mathrm{C}}$

${ }^{a}$ Faculty of Psychology, Universitas Indonesia, Depok, Indonesia; ${ }^{b}$ Department of Clinical Psychology, Faculty of Psychology, Universitas Indonesia, Depok, Indonesia; ${ }^{c}$ Department of Clinical Psychology, Faculty of Psychology, Universitas Indonesia, Depok, Indonesia

*Corresponding author:

Elizabeth Kristi Poerwandari

Department of Clinical Psychology

Faculty of Psychology, Universitas Indonesia

Jl. Lkr. Kampus Raya, Depok, Jawa Barat Indonesia, 16424

Tel.: +62 217270004

Email address: Elizabeth.kristi@ui.ac.id 


\title{
Schizophrenia Behind the Great Jazz
}

\begin{abstract}
Charles "Buddy" Bolden's schizophrenia forced him to play his cornet through improvisation. From that, a new genre of music was born in 1917, known today as jazz. Tom Harrell, a well-known and award-winning jazz musician in the 1970s, also had schizophrenia. Speculations arose about how schizophrenia might contribute to their creativity and finesse in playing music, specifically jazz. By analyzing their cases and stories and reviewing theories and research on schizophrenia and music, this article provides an alternative scientific explanation of how such speculation can be true. This rather new and different perspective on schizophrenia as a severe psychological disorder then might shift people's negative stigma of schizophrenics.
\end{abstract}

Keywords—Buddy Bolden, Tom Harrell, schizophrenia, jazz, improvisation

\section{Introduction}

Jazz has been one of the most popular music genres in the world. Who would have guessed that the man believed to be one of the pioneers of jazz had schizophrenia, a severe psychological disorder that carries a negative stigma in society even today (Gonzalez-Torres, Oraa, Aristegui, Fernandez-Rivas, \& Guimon, 2007; Knight, Wykes, \& Hayward, 2009; Schulze \& Angermeyer, 2003; Vahabzadeh, Wittenauer, \& Carr, 2011; Wood, Britel, Alsawy, Pyle, \& Morrison, 2014). Schizophrenia itself is marked by disturbances in thought, emotion, and behavior that may manifest in disordered thinking in which ideas are not logically related, faulty perception and attention, a lack of emotional expressiveness or inappropriate expressions, and disturbances in movement and behavior, such as a disheveled appearance (Kring, Johnson, Davidson, \& Neale, 2014). Kring et al. (2014) described that people with schizophrenia may withdraw from people and from everyday reality, often into a life of odd beliefs or delusions and hallucinations. Given this definition, it might be hard to imagine someone with schizophrenia producing something that can be enjoyed by many people, let alone a music genre that is now popular; has been known for its sophistication, its typical and integrated improvisation; and can only be played well by musicians with a great deal of ability and skill.

However, the cases of Charles "Buddy" Bolden and one of his successors, Tom Harrell, tell a different story. Their stories tell about two things that at a glance might seem contradictory, schizophrenia and high creativity in playing jazz, but actually work side by side. In fact, given this situation, speculations from a few parties have arisen about how schizophrenia might have contributed to Bolden and Harrell's ability in producing jazz notes (Ballie, 2001; "Mental Illness at the Root of Jazz," 2001). It is important to seek an alternative scientific explanation of how such speculation can be true since there is a negative stigma of schizophrenia (Wood et al., 2014) that contributes to the likelihood of schizophrenics experiencing depression, fear, anxiety, feelings of isolation, guilt, and feelings of shame, and avoiding treatment or seeking help (Dinos, Stevens, Serfaty, Weich, \& King, 2004). 
From that, a new perspective of seeing a mental illness that sees a potential that lies within can emerge and can be noticed. By analyzing Bolden's and Harrell's cases, and reviewing research and theories about music and psychopathology, this paper will answer the following research questions: (1) What alternative scientific explanation can account for how Bolden and Harrell played jazz despite having schizophrenia? (2) What alternative scientific explanation can account for how schizophrenia contributed to Bolden and Harrell's ability in playing jazz music?

\section{Methods}

A qualitative approach using a psychobiography method is used to answer this paper's research questions. We followed the framework for psychobiography research proposed by Robins, Fraley, and Krueger (2007). The first step is choosing the subject. The cases of Bolden and Harrell are chosen because both are influential figures in jazz who suffered from schizophrenia, making them representations of schizophrenics who managed to produce significant work that is enjoyed by a huge audience. Brief biographies of Bolden and Harrell are presented in this paper.

We completed a systematic literature search on information about Bolden and Harrell with no start date and a cut-off date of May 2017. The keywords for the database searches using Google's search engine were "Charles Buddy Bolden" and "Tom Harrell." The sources considered valid literature were those from official sources such as official websites, government websites, news articles, and university websites. Information from other sources was are considered valid and was not used in the analysis. We included information written in English on the topic of Bolden and Harrell's musical ability or schizophrenia. The second step was the formulation of a tentative hypothesis. We initially searched for a same perspective of both music and psychopathology, and the result was the perspective of neuropsychology. Therefore, the tentative hypothesis we developed was that neuropsychology can be used as framework in discussing the case of Bolden and Harrell, thus answering the research questions. The third step was the initial data collection. We completed a systematic search of the literature on neuropsychological theories, music, and schizophrenia with no start date and a cut-off date of May 2017. The literature used were published books, peer-reviewed articles, and gray literature searched with the following keywords: neuropsychology AND music OR jazz OR schizophrenia. We included literature in English on the topic of the neuropsychology of music and neuropsychology of schizophrenia. We screened publications by reading the abstract or summary to remove duplicates, non-English reports, or literature that did not discuss relevant topics. Potentially relevant literature was read in full, except for books in which case just the relevant chapter was read in full. The search was ended once a framework of possible relation between schizophrenia and jazz was obtained. The fourth step was identifying and delimiting valid conclusions. In this step, we created a framework of an alternative scientific explanation that answers the research question. 


\section{Result}

Jazz is a music genre that developed from the end of the 19th century to the beginning of the 20th century (National Park Service, 2015). Born in New Orleans, jazz brought a new color to music with blues and ragtime as its roots. A man believed to be one of the pioneers of jazz was Charles "Buddy" Bolden, a cornet player who was born in 1877 (National Park Service, 2015). Bolden's way of playing the cornet received great recognition among his listeners for its new, unique style (National Park Service, 2015). He played what was known as blues but with a faster tempo and mixed it with ragtime rhythm. Through this, a new music was born with a nuance of freedom. Bolden rose to the top in his musical career, and at one point he even led eight bands at once ("Mental Illness at the Root of Jazz," 2001). However, his career had to come to a halt by the age of 30 (Williams, 2011).

For years, Bolden had suffered from schizophrenia. He had managed the illness for quite a long time until one day, in 1907, he attacked his mother on the street in New Orleans ("Mental Illness at the Root of Jazz," 2001). He then spent his days in the Louisiana Asylum (Williams, 2011) until his death 24 years later ("Mental Illness at the Root of Jazz," 2001).

It takes a special talent to create a new genre of music that is enjoyed by a lot of people, like Bolden did. Bolden displayed a great deal of ability and skill in playing music that set him apart from other musicians. The question is, how did Bolden obtain his ability and skill? There is one perspective that connects Bolden's ability and skill with his illness. This perspective was presented by psychiatrist Dr. Sean A. Spence, MD, of the University of Sheffield, at the Royal College of Psychiatrists Annual Meeting in July 2001 (Ballie, 2001; "Mental Illness at the Root of Jazz," 2001). Spence said that jazz was born from the attempts of a cognitively impaired performer to execute novel performances ("Mental Illness at the Root of Jazz," 2001). According to Spence, Bolden could not properly read music and had impaired motor function due to having schizophrenia, and hence, the only way he could play his instrument was by improvising on popular music from the 1890 s to 1920 s, which is ragtime (Ballie, 2001). In other words, and using the same point of view, there is a possibility that schizophrenia might contribute to the novelty of music being produced. This perspective fits with Bolden's story and it may also fit with Tom Harrell's, another successful jazz player with schizophrenia.

Harrell (born June 16, 1946) first played jazz when he was eight years old (Tom, 2017). He realized that music was his passion, and in 1964, he became a student at Stanford University, majoring in music composition. Later that year, when he was about 18 years old, Harrell attempted suicide (Leung, 2003). According to his sister, Sue Abrahamson, the incident was the first sign of Harrell's mental illness (Leung, 2003). In the summer of 1967, Harrell was diagnosed with schizophrenia (Casey, 2008). His life as a student was quite challenging at times, especially given his illness. Every time Harrell went through "some kind of breakdown" (a term he used in an interview quoted in Casey (2008)) because of his illness, he would leave whatever activity he was doing for several minutes, take his medication, and return to the activity later. Despite such interruptions, Harrell managed to graduate with a Bachelor Degree 
in Art in 1969 (Milkowski, 1998). He then went on tour with Stan Kenton and Woody Herman (Milkowski, 1998).

Around 1970, Harrell became interested in experimental music and played alongside jazz pianist and composer Horace Silver and other bands (Tom, 2017). After that, in 1967, Harrell led his own band. His hard work and high productivity for years led to his success as a jazz musician, composer, and arranger. He was given the title Trumpeter of the Year for three years by DownBeat magazine and received multiple awards from SESAC Jazz Award, Broadcast Music Incorporated Composers Award, and Prix Oscar du Jazz (Tom, 2017). His album “Time's Mirror” received a Grammy Award nomination.

\section{A. An alternative scientific explanation on how Bolden and Harrell still managed to play jazz} despite having schizophrenia

Before discussing how schizophrenia might have contributed to Bolden and Harrell's ability to play jazz, schizophrenia itself should be discussed. Symptoms of schizophrenia can be divided into two types, positive symptoms and negative symptoms (Picchioni \& Murray, 2007). Positive symptoms include a lack of insight or failure to appreciate that symptoms are not real or caused by illness, hallucination or perception without a stimulus, delusions or a fixedly held false belief that is not shared by others from the patient's community, and thought disorder that manifests as distorted or illogical speech; while negative symptoms include social withdrawal, self-neglect, loss of motivation and initiative, emotional blunting, and paucity of speech. Related to the causes of schizophrenia, Gilmore (2010) stated that schizophrenia is an end result of a complex interaction between thousands of genes and multiple environmental risk factors and that there is no single thing that causes schizophrenia. However, schizophrenia is increasingly considered a subtle neurodevelopmental disorder of brain connectivity, which is how the functional circuits in the brains are wired (Gilmore, 2010). Kring et al. (2014) also stated that schizophrenia is closely related to how the brain works.

The ability to play jazz can be understood through the perspective of neuroscience and psychology (Levitin \& Tirovolas, 2009). Therefore, the approach that will be taken to explain how schizophrenia might contribute to Bolden and Harrell's musicality is neuropsychology.

Jazz, according to Berliner (McPherson \& Limb, 2013), is a form of music that is flexible and diverse, as well as a form that involves several conventions and norms such as limitation in using key, tempo, meter, and mode. One of the identifying characteristics of a jazz performance is the improvisation done by its players. Musical improvisation, as stated by Loui (2018), is a subset of creativity with real-time constraints and involves a complex system. When professional jazz musicians improvise, they are making immediate decisions about the musical phrases they wish to produce (Lopez-Gonzalez \& Limb, 2012). Improvising is neither easy nor simple because the musician has to produce musical phrases that are contextually meaningful by combining a set of notes and rhythms (Lopez-Gonzalez \& Limb, 2012) and other musical attributes including pitch, timbre, tempo, meter, contour, and loudness (Pierce, in Levitin \& Tirovolas, 2009). In line with this, Beaty (2015) stated that improvising is one of the most complex forms of creative behavior, in which the musician has to manage several 
processes simultaneously in real time such as making and evaluating melodic and rhythmic sequence, coordinating performance with other musicians in an ensemble, and executing elaborative motor movement, with the intention of creating music that is aesthetically appealing. As stated by McPherson and Limb (2013), spontaneous improvisation, particularly in jazz, is the most developed and advanced form of music improvisation and various studies have been conducted to understand the higher process of musical improvisation, improvisation by jazz musicians.

Limb and Braun's (2008) study using a neuropsychological perspective found that spontaneous improvisation in a musical performance, including in jazz and independent from its musical complexity, is marked by deactivation in a lateral portion of the prefrontal cortex parallel with an activation in the medial prefrontal cortex. This unique pattern indicates an intrinsic cognitive dissociation in a creative process that produces novel material such as a particular nuance of music in an improvised musical performance. In line with this finding, Levitin and Tirovolas (2009) described that professional musicians who perform improvisation are involved in an automatic process of music in a sub or preconscious domain of control and consciousness. Related to this, Dietrich (in Limb \& Braun, 2008) mentioned that creativity in a spontaneous musical performance is often regarded as the most mysterious form of creative behavior, occurring in an altered state of mind that transcends awareness or control. These findings are supported by various studies including Pressing (Beaty, 2015), who stated that improvisational fluency relies on an automated process that requires minimal attention awareness, and McPherson and Limb (2013), who stated that while improvising, particularly jazz, musicians enter a total state of focus, known as a flow state, in which creativity becomes almost effortless and the musicians are not necessarily required to do conscious thinking of the actions taken. Therefore, one of the alternative scientific explanations of how Bolden and Harrell managed to play jazz despite having schizophrenia is that improvisation, according to the findings above, occurs outside of consciousness.

\section{B. An alternative scientific explanation on how schizophrenia might contribute Bolden and} Harrell's ability

Although improvisation is said to occur outside of consciousness, literature has shown that it also involves activation in different areas of the brain. Earlier theories stated that the right hemisphere of the brain plays a dominant role in musical performance (Joseph, 1988). However, Levitin and Tirovolas (2009) argue that this is an excessive simplification of the musical mechanism. Later studies that found the appearance and composition of music involves various areas of the brain, bilaterally, in the cortex and cerebellum. However, the importance lies in two perspectives related to the brain (Schlaug, in Peretz \& Zatorre, 2003). First is that the brain has plasticity, meaning that it allows changes in function and structure as a result of frequent usage, including the use of music. Second is that a person's brain already has a certain predisposition before the person gains specific skills. Therefore, it is not a surprise that there are differences in some aspects of musicians' brains when compared to nonmusicians, such as a bigger anterior in the corpus callosum, bigger precentral gyrus symmetry in the motor cortex, and higher gray matter concentrate in several areas including the perirolandic, posterior superior parietal, posterior medial perisylvian, and cerebellum 
(Schlaug, in Peretz \& Zatorre, 2003). Berkowitz and Ansari (2008) found, based on melodic improvisation main effect analysis, that there was a difference in the mechanism of the brain between musicians and non-musicians, namely, a deactivation of the right temporoparietal junction (TPJ) in the brains of musicians. The musician's ability to deactivate right TPJ while improvising indicates neuropsychological changes associated with a person's musical skill.

Another important aspect that should be highlighted is the function of jazz itself as a form of expression. Based on Hentoff (in Limb \& Braun, 2008), improvisation in jazz is regarded as a very individual expression of its musicians. One of the key factors that plays a role in this is emotion, which is mediated by the limbic system (Limb \& Braun, 2008). The emotions and emotional appreciation of each musician may be different, resulting in different musical products (Limb \& Braun, 2008). In line with this, Levitin and Tirovolas (2009) described that music can be seen as a form of artistic expression, communication, and self-discovery that represents the dynamic form of emotion (Langer, in Levitin \& Tirovolas, 2009). Mula and Trimble (2009) stated that music is a form of communication to express emotional meaning through high-registered socially accepted patterned sound. This connection between emotion and music is also supported by Trimble and Hesdorffer (2017), who explained that the link between music and emotion has been accepted over time and that one can be moved emotionally by music. Expressing emotion is also said to be the essence of music (Nietzsche, in Levitin \& Tirovolas, 2009), including in jazz.

The symptoms of schizophrenia had negative effects on both Bolden's and Harrell's lives. However, these symptoms may also have played a role in their musical ability and skill, particularly in jazz. Several perspectives have been proposed related to the connection between schizophrenia and creativity. Kaufman and Paul (2014), among others, stated that schizophrenia by its nature disposes toward satisfying one requirement for creativity, namely, originality. It is based on the idea that schizophrenic thoughts are more likely to be unique or new. However, specifically related to schizophrenia and jazz, there are other possible connections. This connection is quite important to address because it may bring a new perspective on seeing schizophrenia as an illness, that is, how schizophrenia might contribute to musical ability.

As mentioned earlier, there are certain conditions that schizophrenics have to live with. First is having impaired cognition, and second is having a limited ability to express emotion. Having impaired cognition means having to play music in a certain way. This perspective has been proposed by Spence, who described that Bolden had to improvise because there were no other ways for him to play music. Spence's perspective could be further explained with findings that show improvisation occurs outside of consciousness (Limb \& Braun, 2008; Levitin \& Tirovolas, 2009). Music that is played according to a certain reference, such as musical notes or music that has been played before, requires a conscious cognitive process. Due to having schizophrenia, Bolden had impaired cognition, so playing music according to a certain reference might not have been possible for him. Improvising, on the other hand, does not involve the conscious cognitive process and was a way for him to play music. The same can be said for Harrell. 
The other condition is having a limited ability to express emotion. This is due to having one of the symptoms of schizophrenia, which is blunted affect or lacking in outward expression of emotion (Kring et al., 2014) indicated by a disturbance in the amygdala system (Kring \& Caponigro, 2010). Schizophrenics tend not to express their emotions through facial expression even when they are experiencing an emotion as intense as a normal person (Kring et al., 2014). Given Bolden and Harrell's schizophrenia, there is a great chance they had this symptom. The importance, however, lies in the function of jazz as a form of expression.

Due to having an impaired mechanism in expressing emotion, Bolden's and Harrell's brains might have developed alternative neural connections to compensate for the condition. This probability is related to the functional compensation principle of the brain, which is a process in which individuals with a central nervous system disorder, including the brain, compensate for the disorder through the adaptive implementation of behavioral, cognitive, or physical strategies designed to improve their remaining skills or produce alternative skills (Duca \& Rose, 2011). In Bolden's and Harrell's cases, the alternative skills produced are possibly the ones related to playing music, especially given that music has a function of expressing emotion, which they lacked.

Given that the brain has plasticity, as mentioned earlier, the conditions that Bolden and Harrell had due to their illness might have led to the start and reinforcement of their jazz improvisation and therefore changed the structure of their brains, leading to an enhancement of their playing ability. Another possible factor that allowed Bolden and Harrell to keep playing their instruments would be jazz as a form of music and how it affects their brain. Disorderliness is a symptom of schizophrenia, and various studies have confirmed that music can act as a therapy (Gold, Heldal, Dahle, \& Wigram, 2005; Gold, Solli, Kruger, \& Lie, 2009; Mossler, Chen, Heldal, \& Gold, 2011; Solanki, Zafar, \& Rastogi, 2013). This function of music as therapy might also have reinforced Bolden and Harrell's jazz improvisation.

\section{Conclusion}

Despite having impaired cognition, the fact that both Bolden and Harrell managed to play jazz can be explained by findings that show improvisation occurs outside of consciousness and no conscious cognitive decisions need to be made in improvisation. Also, there is a scientific alternative explanation that connects schizophrenia with jazz through the perspective of neuropsychology, namely, the functional compensation principle of brain. If Bolden and Harrell had an impaired mechanism in expressing emotion, it is possible that they developed alternative skills related to playing music, given music's function of expressing emotion. Since the brain has plasticity, Bolden and Harrell's symptoms of schizophrenia might have led to the start and reinforcement of their jazz improvisation and therefore changed the structure of their brains, which led to an enhancement of their playing ability. 


\section{Discussion}

Symptoms of schizophrenia affect many aspects of one's life, including how one thinks, feels, and behaves (Kring et al., 2014). It is not a surprise, then, that these symptoms might lead sufferers to have difficulty in maintaining a job, living independently, and having close relationships with other people (Kring et al., 2014). Even so, when someone has schizophrenia it does not mean that he or she cannot produce or create something that can be enjoyed by others or even make positive contributions to society. Other examples beside Bolden and Harrell include Syd Barrett, founder of the famous rock band Pink Floyd; John Nash, founder of game theory; and Vaslav Nijinsky, legendary dancer and choreographer, who all suffered from schizophrenia (Burton, 2015). There is a possibility that schizophrenics can achieve success or even excel in a particular field due to their condition. Although further research is needed, this way of thinking should alter the negative stigma of schizophrenia. This point becomes important because according to Dinos, Stevens, Serfaty, Weich, and King (2004), schizophrenics report experiencing verbal abuse, physical abuse, loss of contact with others, and overt discrimination. As a result, they are likely to experience depression, fear, anxiety, feelings of isolation, guilt, and feelings of shame, and to avoid treatment or seeking help (Dinos et al., 2004). Therefore, instead of stigmatizing and isolating schizophrenics because of their symptoms, it would be much better if they were seen as having potential. With this view, a more positive environment can be created and opportunities can be opened up to schizophrenics. However, looking at the positive side of schizophrenia does not mean disregarding its symptoms. It means that rather than making the symptoms of schizophrenia into a stigma, it would be helpful to consider them as characteristics that can provide benefits as well as need treatment.

Besides providing a new perspective on schizophrenia as a means to counter the negative stigma of people with the illness, this discussion can serve as a basis for future research related to mental illness, such as music therapy as an intervention and the association between mental illness and creativity.

\section{References}

Ballie, R. (2001). The melody behind mental illness. APA. Retrieved from http://www.apa.org/monitor/oct01/melody.aspx.

Beaty, R. E. (2015). The neuroscience of musical improvisation. Neuroscience and Behavioral Reviews, 51, $108-117$.

Berkowitz, A. L., \& Ansari, D. (2008) Generation of novel motor sequences: the neural correlates of musical improvisation. NeuroImage, 41, 535-543.

Burton, N. (2015, Sep 23). Mad genius: schizophrenia and creativity. Psychology Today. Retrieved from: https://www.psychologytoday.com/blog/hide-and-seek/201509/mad-genius-schizophrenia-and-creativity.

Casey, C. (2008, n.d.). Making Music that Catches the Wind. Stanford Magazine. Retrieved from https://alumni.stanford.edu/get/page/magazine/article/?article_id=32012.

Dinos, S., Stevens, S., Serfaty, M., Weich, S., \& King, M. (2004). Stigma: the feelings and experiences of 46 people with mental illness. British Journal of Psychiatry, 184, 176-181.

Duca, L., \& Rose, J. (2011). Functional compensation. In J. S. Kreutzer, J. DeLuca, \& B. Caplan (eds), Encyclopedia of Clinical Neuropsychology. New York: Springer. 
Gilmore, J. H. (2010). Understanding what causes schizophrenia: A developmental perspective. The American Journal of Psychiatry, 167(1), 8-10.

Gold, C., Heldal, T. O., Dahle, T., \& Wigram, T. (2005) Music therapy for schizophrenia or schizophrenia-like illnesses. Cochrane Database of Systematic Reviews 2005, Issue 2. Art. No.: CD004025. DOI: 10.1002/14651858.CD004025.pub2.

Gold, C., Solli, H. P., Kruger, V., \& Lie, S. T. (2009). Dose-response relationship in music therapy for people with serious mental disorders: Systematic review and meta-analysis. Clinical Psychology Review, 29(3), 193-207.

Gonzalez-Torres, M. A., Oraa, R., Aristegui, M., Fernandez-Rivas, A., \& Guimon, J. (2007). Stigma and discrimination towards people with schizophrenia and their family members. Social Psychiatry and Psychiatric Epidemiology, 42(1), 14-23.

Joseph, R. (1988). The right cerebral hemisphere: emotion, music, visual-spatial skills, body-image, dreams, and awareness. Journal of Clinical Psychology, 44(5), 630-673.

Kaufman, S. B., \& Paul, E. S. (2014). Creativity and schizophrenia spectrum disorders across arts and sciences. Frontiers in Psychology, 5(1145), 1-4.

Knight, M. T., Wykes, T., \& Hayward, P. (2009). 'People don't understand': An investigation of stigma in schizophrenia using interpretative phenomenological analysis (IPA). Journal of Mental Health, 12(3), 209-222.

Kring, A. M., \& Caponigro, J. M. (2010). Emotion in schizophrenia: Where feeling meets thinking. Current Direction Psychological Science, 19(4), 255-259.

Kring, A. M., Johnson, S. L., Davison, G., \& Neale J. (2014) Abnormal psychology 12th Ed. USA: Wiley.

Leung, R. (2003, Aug 19). A beautiful note: Jazz trumpeter overcomes paranoid schizophrenia through music. CBS News. Retrieved from https://www.cbsnews.com/news/a-beautiful-note/.

Levitin, D. J., \& Tirovolas, A. K. (2009). Current advances in the cognitive neuroscience of music. Annals of the New York Academy of Sciences, 1156, 211-231.

Limb, C. J., \& Braun, A. R. (2008). Neural substrates of spontaneous musical performance: An fMRI study of jazz improvisation. PLoS ONE, 3(2). Doi: https://doi.org/10.1371/journal.pone.0001679.

Lopez-Gonzalez, M., \& Limb, C. J. (2012). Musical creativity and brain. Cerebrum, 2.

Loui, P. (2018). Rapid and flexible creativity in musical improvisation: Review and a model. Annals of the New York Academy of Sciences, 1-8.

McPherson, M., \& Limb, C. J. (2013). Difficulties in the neuroscience of creativity: Jazz improvisation and the scientific method. Annals of the New York Academy of Sciences, 1-4.

Mental Illness at the Roots of Jazz. (2001, Jul 10). BBC News. Retrieved from http://news.bbc.co.uk/2/hi/health/1430337.stm.

Milkowski, B. (1998). Tom Harrell: Senses and sensibilities. North Carolina Central University: Jazz Times. Retrieved from https://jazztimes.com/features/tom-harrell-senses-and-sensibilities/.

Mossler, K., Chen, X., Heldal, T. O., \& Gold, C. (2011). Music therapy for people with schizophrenia and schizophrenia-like disorders. Cochrane Database of Systematic Reviews 2011, Issue 12. Art. No.: CD004025. DOI: 10.1002/14651858.CD004025.pub3.

Mula, M., \& Trimble, M. (2009). Music and madness: Neuropsychiatric aspects of music. Clinical Medicine, 9(1), 83-86.

National Park Service. (2015). Charles 'Buddy' Bolden. Retrieved from https://www.nps.gov/jazz/learn/historyculture/bolden.htm.

Picchioni, M. M., \& Murray, R. M. (2007). Schizophrenia. BMJ, 335 (7610), 91-95.

Robins, R. W., Fraley, R. C., \& Krueger, R. F. (2007). Handbook of research methods in personality psychology. New York: The Guilford Press.

Schlaug, G. (2003). The brain of musicians. In I. Peretz, \& R. J. Zatorre (Ed.), The cognitive neuroscience of music (pp. 366-381). New York: Oxford University Press Inc.

Schulze, B., \& Angermeyer, M. C. (2003). Subjective experiences of stigma. A focus group study of schizophrenic patients, their relatives and mental health professionals. Social Science and Medicine, 56(2), 299-312. 
Solanki, M. S., Zafar, M., \& Rastogi, R. (2013). Music as a therapy: Role in psychiatry. Asian Journal of Psychiatry, 6(3), 193-199.

Tom Harrell. (2017). Official Site of Tom Harrell. Retrieved from http://www.tomharrell.com.

Trimble, M., \& Hesdorffer, D. (2017). Music and the brain: the neuroscience of music and musical appreciation. BJPSYCH International, 14(2), 28-31.

Vahabzadeh, A., Wittenauer, J., \& Carr, E. (2011). Stigma, schizophrenia and the media: Exploring changes in the reporting of schizophrenia in major U.S. newspapers. Journal of Psychiatric Practice, 17(6), 439446.

Williams, R. (2011). Buddy Bolden 'invents' jazz. The Guardian. Retrieved from https://www.theguardian.com/music/2011/jun/17/buddy-bolden-invents-jazz.

Wood, L., Britel, M., Alsawy, S., Pyle, M., \& Morrison, A. (2014). Public perceptions of stigma towards people with schizophrenia, depression, and anxiety. Psychiatry Research, 220, 204-208 